\title{
THE LEGAL DEFINITION OF "RADIOACTIVE WASTE" IN EU LAW AND THE LEGISLATION OF THE RUSSIAN FEDERATION
}

\author{
Yulia V. Lebedeva \\ The Ministry of Foreign Affairs of the Russian Federation, Moscow G-200, Russian Federation
}

\begin{abstract}
Introduction: the adoption of the legal definition of "radioactive waste" in the Russian legislation and EU law was a significant event, as it reflected the importance of understanding the dangers to humans and the environment that humanity faced when dealing with radiation. The purpose of the study was to adopt one of the main legal concepts in atomic law - "radioactive waste". Methods: the methodological framework for the research is a set of methods of scientific knowledge, among which the main ones are the general scientific philosophical methods of dialectical and historical materialism, the methods of comparative law, consistency, the methods of logical and structural and functional analysis. Results: the author's well-founded position is based on the Russian legislation, EU law, and the opinions of the competent Soviet, Russian, and foreign scientific community on the issue of adopting a legal definition of "radioactive waste". Based on the comparative legal analysis of the norms of the Federal laws of the Russian Federation and EU Directives, the differentiation of characteristic features of the legal definition of "radioactive waste" in EU law and the Russian legislation is carried out. Its features in Russian law are revealed. Conclusions: the study revealed the role of a unified legal approach to the legal definition of "radioactive waste" in order to explore the possibility of starting negotiations between the EU and Russia to develop an agreement in the field of scientific research of processing and new ways of disposal of radioactive waste.

Key words: legal definition of "radioactive waste", EU law, Russian law "On the Use of Atomic Energy", EU Directive on spent nuclear fuel and radioactive waste, Law "On Radioactive Waste Management and Amendments to Certain Legislative Acts of the Russian Federation", legal term "accumulated radioactive waste".

Citation. Lebedeva Yu.V. The Legal Definition of "Radioactive Waste" in EU Law and the Legislation of the Russian Federation. Legal Concept, 2020, vol. 19, no. 2, pp. 116-120. (in Russian). DOI: https://doi.org/10.15688/ lc.jvolsu.2020.2.17
\end{abstract}

\section{ПРАВОВОЕ ОПРЕДЕЛЕНИЕ «РАДИОАКТИВНЫЕ ОТХОДЫ» В ПРАВЕ ЕС И ЗАКОНОДАТЕЛЬСТВЕ РОССИЙСКОЙ ФЕДЕРАЦИИ}

\author{
Юлия Вячеславовна Лебедева
}

Министерство иностранных дел Российской Федерации, г. Москва Г-200, Российская Федерация

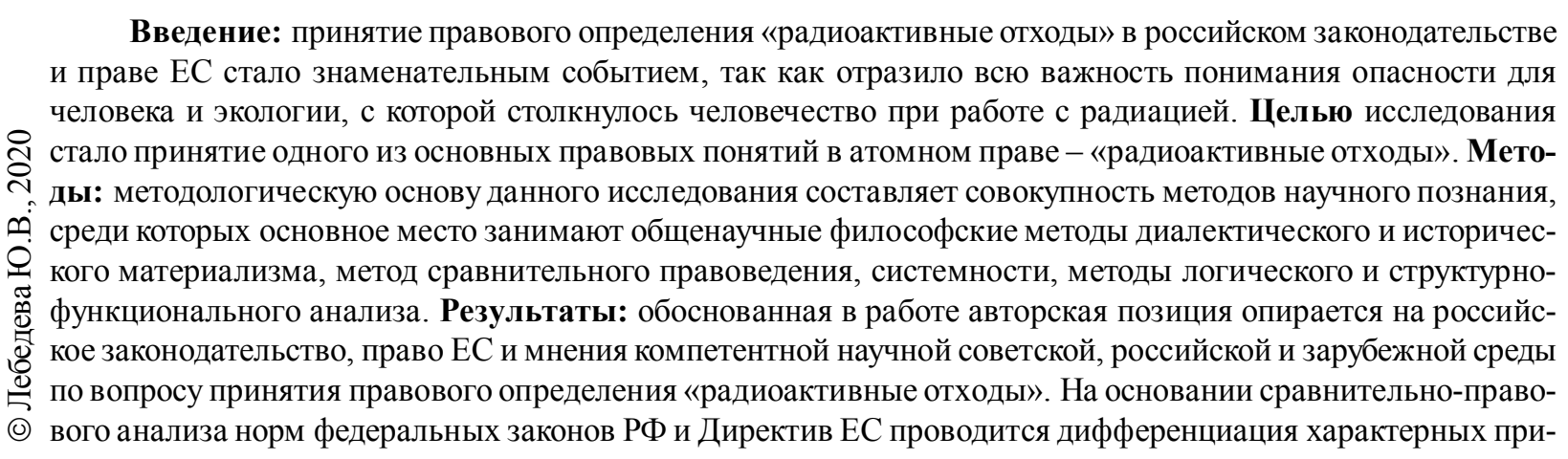


знаков правового определения «радиоактивные отходы» в праве ЕС и российском законодательстве. Раскрываются его особенности в российском праве. Вывод: в результате исследования выявлена роль единого правового подхода к правовому определению «радиоактивных отходов» с целью изучения возможности для начала переговоров между ЕС и Россией по выработке соглашения в области научного исследования переработки и новых способов захоронения радиоактивных отходов.

Ключевые слова: правовое определение «радиоактивные отходы», право ЕС, российский закон «Об использовании атомной энергии», Директива ЕС об отработавшем ядерном топливе и радиоактивных отходах, закон «Об обращении с радиоактивными отходами и о внесении изменений в отдельные законодательные акты Российской Федерации», правовой термин «накопленные радиоактивные отходы».

Цитирование. Лебедева Ю. В. Правовое определение «радиоактивные отходы» в праве ЕС и законодательстве Российской Федерации // Legal Concept = Правовая парадигма. -2020 . - T. 19, № 2. - C. 116-120. - DOI: https://doi.org/10.15688/lc.jvolsu.2020.2.17

\section{Введение}

Правовые определения являются основным понятийным инструментом в решении задач правового регулирования, которые обеспечивают единый подход в понимании ключевых явлений, происходящих в обществе. Принятие новых правовых понятий, определений и терминов является объективным и неотъемлемым процессом развития общественных отношений. Единая правовая терминология на международном уровне играет огромную роль в достижении к сближению позиций государств за столом переговоров и четкого понимания предмета переговоров, и, как следствие, способствует развитию научного и экономического двустороннего и многостороннего сотрудничества между странами.

Вопрос о выработке правового определения «радиоактивные отходы» в атомном праве и о правовом урегулировании утилизации радиоактивных отходов, которые начали увеличиваться с каждым годом по всей планете, встал сразу же после роста рынка изотопной продукции, радиофармпрепаратов, источников ионизирующего излучения, от деятельности атомной энергетики, военно-промышленного комплекса, ядерной медицины и добывающих отраслей как на территории России, так и на территории ЕС. Как отмечал А.И. Иойрыш: «Развитие атомной промышленности и широкое применение радиоактивных изотопов сопровождаются накоплением большого количества радиоактивных отходов. Вопрос о рациональном способе ликвидации этих отходов стал за последние годы одним из важнейших» [1, с. 158-159].
В середине XX в. правовое определение «радиоактивные отходы» каждое государство попыталось сформулировать в нормативнотехнических документах ведомственного характера, которые имели ограниченный доступ пользования, так как все атомные исследования в основном были засекречены и связаны с вопросами безопасности государства. В конце прошлого столетия человечество столкнулось с экологическими проблемами, осознало всю опасность радиоактивных отходов и получило отрицательный опыт их утилизации для всей экосистемы нашей планеты. Эту мысль в своих работах озвучили советские академики П.Н. Бургасов, А.М. Петросьянц, профессор А.И. Иойрыш, а также ряд зарубежных авторов по европейскому праву М. Рока, Л. Шейнман, Д.Д. Смит, А. Сёдерстен. Поэтому многие страны в 90-х гг. прошлого века сформулировали правовое определение «радиоактивные отходы» в своих национальных законодательствах, приняв регулирующие законы на федеральном уровне, а также в ЕС были приняты ряд директив, а на международном уровне в рамках МАГАТЭ была разработана и подписана в 1997 г. «Объединенная конвенция о безопасности обращения с отработавшим топливом и о безопасности обращения с радиоактивными отходами».

\section{Сравнительный анализ правового определения «радиоактивные отходы» в европейском и российском праве}

Впервые российское законодательство открыто сформулировало правовое определение «радиоактивные отходы» в ст. 3 Федераль- 
ного закона «Об использовании атомной энергии» от 21 ноября 1995 г. № 170-ФЗ: радиоактивные отходы - «это ядерные материалы и радиоактивные вещества, дальнейшее использование которых не предусматривается» [2, ст. 4552]. В праве ЕС было введено правовое определение «радиоактивные отходы» немного раньше, в 1992 г. Директивой Совета 92/3/ Евратом «О надзоре и контроле над перевозками радиоактивных отходов между государствами-членами ЕС и в Сообщество и из него». Европейское право определило радиоактивные отходы, как «любой материал, который содержит или загрязнен радионуклидами и для которого дальнейшее использование не предусматривается» [4, с. 25]. Таким образом, подход в начале 90-х гг. ХХ в. был в целом одинаков - это то, что в скором будущем радиоактивные отходы не могли использоваться в дальнейшем производстве.

В 2011 г. было принято новое правовое определение «радиоактивные отходы» в праве ЕС, данное в п. 7 ст. 3 Директивы ЕС 2011/70 «Об отработавшем ядерном топливе и радиоактивных отходах» $[5$, с. 50], которое полностью совпадает с понятием радиоактивных отходов в международном ядерном праве, сформулированным в ст. 2 «Объединенной конвенции о безопасности обращения с отработавшим топливом и о безопасности обращения с радиоактивными отходами» 1997 года [6, c. 68]. А именно, радиоактивные отходы - это радиоактивный материал в газообразном, жидком или твердом состоянии, дальнейшее использование которого не предусматривается и который будет контролироваться регулирующим органом в рамках национального законодательства, то есть каждым государствомчленом ЕС в рамках своего законодательства. Директива ЕС 2011/70 сделала отсылку на законодательство стран-членов ЕС. Таким образом, национальное законодательство каждого государства-члена ЕС регулирует вопросы надзорного компетентного органа и контроля за радиоактивными отходами и их утилизацией. Данное правовое определение используется в европейском праве до настоящего времени.

В Российской Федерации в 2011 г. начал действовать единственный основополагающий закон в области обращения с радиоак- тивными отходами - это Федеральный закон «Об обращении с радиоактивными отходами и о внесении изменений в отдельные законодательные акты Российской Федерации» от 11 июля 2011 г. № 190-Ф3, в котором было четко сформулировано новое правовое определение «радиоактивные отходы». Правовое понятие «радиоактивные отходы», данное в № 170-Ф3, стало применяться в измененной редакции в значении, предусмотренном ст. 3 Федерального закона № 190-ФЗ. В соответствии с измененной редакцией радиоактивные отходы - это «не подлежащие дальнейшему использованию материалы и вещества, а также оборудование, изделия (в том числе отработавшие источники ионизирующего излучения), содержание радионуклидов в которых превышает уровни, установленные в соответствии с критериями, установленными Правительством Российской Федерации» [3, ст. 4281]. В соответствии с Федеральным законом № 190-ФЗ радиоактивными отходами «могут признаваться материалы с повышенным содержанием природных радионуклидов, образовавшиеся при осуществлении не связанных с использованием атомной энергии видов деятельности по добыче и переработке минерального и органического сырья с повышенным содержанием природных радионуклидов, в случае, если эти материалы не подлежат дальнейшему использованию». Таким образом, Федеральный закон № 190-ФЗ расширяет понятие «радиоактивные отходы», включая в правовое понятие «материалы с повышенными природными радионуклидами, не подлежащие использованию в дальнейшем», образующиеся от добычи и переработки природного радиационного сырья.

В отличие от российского законодательства право ЕС в правовом определении «радиоактивные отходы» делает акцент на классификацию по агрегатному состоянию, то есть разделяет радиоактивные отходы на жидкие, газообразные и твердые, а также на контроль за радиоактивными отходами со стороны национального регулирующего органа странычлена ЕС. Как российский, так и европейский законодатели правовую дефиницию «радиоактивные отходы» определили, как радиоактивный материал, который дальнейшему использованию не подлежит. Подход к правовому оп- 
Ю.В. Лебедева. Правовое определение «радиоактивные отходы» в праве ЕС и законодательстве РФ

ределению «радиоактивные отходы», как к объекту правового регулирования, в российском и европейском праве в основном остается единым.

\section{Особенность правового определения «радиоакти вные отходы» в российском законодательстве}

В то же время следует отметить, что российский законодатель к радиоактивным отходам относит не только материалы, но и вещества, оборудования и изделия, в том числе отработавшие источники ионизирующего излучения, то есть детализирует понятие, расширяя его рамки. Правовое определение «радиоактивные отходы» является бланкетной нормой, то есть ссылается на законодательные акты Российской Федерации, в которых прописаны критерии классификации радиоактивных отходов в соответствии с уровнем содержания радионуклидов в целом, то есть ссылка выражена в самой общей форме, отсылая к другим российским законодательным актам, без указания на конкретную статью, где можно найти недостающие сведения. При бланкетном изложении, которое российский законодатель использовал для дачи правового определения «радиоактивные отходы», норма остается неопределенной, открывая возможность для законодателя усовершенствовать ее с помощью других правовых актов.

Особенностью стало также и то, что ядерные отходы накапливались сначала в CCCP, а потом в Российской Федерации в связи с развитием атомной промышленности не только в мирных целях, но и в военных, соответственно объем радиоактивных отходов увеличивался, и необходимо было искать решение проблемы окончательного хранения ядерных отходов. Поэтому российский законодатель Федеральным законом № 190-Ф3 устанавливает правовое понятие «накопленные радиоактивные отходы» - «радиоактивные отходы, образовавшиеся до дня вступления в силу настоящего Федерального закона и внесенные в реестр радиоактивных отходов в порядке, установленном настоящим Федеральным законом» [3, ст. 4281]. Введение нового правового термина позволило идентифи- цировать радиоактивные отходы, образованные во времена СССР, определив им место в российском законодательстве, и окончательно урегулировать этот вопрос в российском атомном праве.

\section{Выводы}

С учетом роста изотопной экономики и новых цифровых технологий в ядерной энергетике открываются новые направления для научных и исследовательских связей между Россией и со странами-членами ЕС, в том числе с такими важными российскими партнерами, как Франция, Болгария, Германия, Италия. Принимая во внимание единый правовой подход в ЕС и России к определению «радиоактивные отходы», появляется возможность изучения и проработки вопроса заключения ряда двусторонних соглашений между Россией и странами-членами ЕC, а также соглашения между Росатомом и Евратомом по созданию совместных проектов в области научных исследований по переработке радиоактивных отходов с целью снижения уровня их радиоактивности и поиска новых форм захоронения.

\section{СПИСОК ЛИТЕРАТУРЫ}

1. Иойрыш, А. И. Концепция атомного права / А. И. Иойрыш. - М. : ЮНИТИ-ДАНА, 2008. -719 с.

2. Федеральный закон от 21 ноября 1995 г. № 170-Ф3 «Об использовании атомной энергии» (с изм. и доп.) // Собрание законодательства РФ.1995. - № 48. - Ст. 4552.

3. Федеральный закон от 11 июля 2011 г. № 190-Ф3 «Об обращении с радиоактивными отходами и о внесении изменений в отдельные законодательные акты Российской Федерации» // Собрание законодательства РФ. - 2011. - № 29. - Ст. 4281.

4. Council Directive 92/3/Euratom of 3 February 1992 on the supervision and control of shipments of radioactive waste between Member States and into and out of the Community // Official Journal of the EU. -1992. - № 35. - P. 24-28.

5. Council Directive 2011/70/EURATOM of 19 July 2011 establishing a Community framework for the responsible and safe management of spent fuel and radioactive waste // Official Journal of the EU. 2011. - № 199. - P. 48-56.

6. Joint Convention on the Safety of Spent Fuel Management and on the Safety of Radioactive 
Waste Management // Compendium of International Legal Instruments in the Nuclear Energy Field. Part I. - International School of Nuclear Law. - France, University of Montpellier, AEN NEA, 2008. - P. 67-81.

\section{REFERENCES}

1. Ioyrysh A.I. Kontseptsiya atomnogo prava [The Concept of Atomic Law]. Moscow, YuNITIDANA Publ., 2008. 719 p.

2. Federalnyy zakon ot 21 noyabrya $1995 \mathrm{~g}$. № 170-FZ «Ob ispolzovanii atomnoy energii» (s izm. i dop.) [Federal Law "On the Use of Atomic Energy" (as Amended and Additional) of November 21, 1995, No. 170-FL]. Sobraniye zakonodatelstva RF [Collection of Legislation of the Russian Federation], 1995, no. 48, art. 4552.

3. Federalnyy zakon ot 11 iyulya 2011 g. № $190-\mathrm{FZ}$ «Ob obrashchenii s radioaktivnymi otkhodami i o vnesenii izmeneniy $\mathrm{v}$ otdelnyye zakonodatelnyye akty
Rossiyskoy Federatsii» [Federal Law "On the Management of Radioactive Waste and on Amending Certain Legislative Acts of the Russian Federation" of July 11, 2011 No. 190-FL]. Sobraniye zakonodatelstva $R F$ [Collection of Legislation of the Russian Federation], 2011, no. 29, art. 4281.

4. Council Directive 92/3/Euratom of 3 February 1992 on the supervision and control of shipments of radioactive waste between Member States and into and out of the Community. Official Journal of the EU, 1992, no. 35, pp. 24-28.

5. Council Directive 2011/70/EURATOM of 19 July 2011 establishing a Community framework for the responsible and safe management of spent fuel and radioactive waste. Official Journal of the EU, 2011, no. 199 , pp. 48-56.

6. Joint Convention on the Safety of Spent Fuel Management and on the Safety of Radioactive Waste Management. Compendium of International Legal Instruments in the Nuclear Energy Field, Part I, International School of Nuclear Law, France, University of Montpellier, AEN NEA, 2008, pp. 67-81.

\section{Information About the Author}

Yulia V. Lebedeva, Candidate for a Degree, Department of European Law, MGIMO University of the Ministry of Foreign Affairs of the Russian Federation, Adviser, Historical and Documentary Department of the Ministry of Foreign Affairs of the Russian Federation, The Ministry of Foreign Affairs of the Russian Federation, Smolenskaya-Sennaya Sq., 32/34, 119200 Moscow G-200, Russian Federation, y.lebedeva.68@mail.ru,https://orcid.org/0000-0003-4902-1657

\section{Информация об авторе}

Юлия Вячеславовна Лебедева, соискатель кафедры европейского права МГИМО МИД России, советник Историко-документального департамента МИД России, Министерство иностранных дел Российской Федерации, Смоленская-Сенная площадь, 32/34, 119200 г. Москва Г-200, Российская Федерация, y.lebedeva.68@mail.ru, https://orcid.org/0000-0003-4902-1657 